\title{
Uniparental Isodisomy of Chromosome 1 Unmasking an Autosomal Recessive 3-Beta Hydroxysteroid Dehydrogenase Type II-Related Congenital Adrenal Hyperplasia
}

\author{
Karin Panzer ${ }^{1}$, Osayame A. Ekhaguere², Benjamin Darbroํ, Jennifer Cook ${ }^{3}$, Oleg A. Shchelochkov1* \\ 1 University of lowa Hospitals and Clinics, Stead Department of Pediatrics, lowa, USA \\ 2The Children's Hospital of Philadelphia, Division of Neonatal and Perinatal Medicine, Philadelphia, USA \\ 3Blank Children's Hospital, Department of Pediatric Endocrinology, lowa, USA \\ *Current Institution: National Human Genome Research Institute, Bethesda, Maryland, USA
}

\section{What is already known on this topic?}

3-beta hydroxysteroid dehydrogenase type II (3 $\beta$-HSD2) deficiency is a rare form of congenital adrenal hyperplasia (CAH) that is inherited in an autosomal recessive manner, typically with one gene variant inherited from each parent. Uniparental isodisomy (UPD) as the genetic basis of $\mathrm{CAH}$ has been reported in other forms of $\mathrm{CAH}$.

\section{What this study adds?}

The first reported case of 3 $\beta$-HSD2 deficiency arising from UPD of chromosome 1.

\begin{abstract}
Steroid 3-beta hydroxysteroid dehydrogenase type II (3 $\beta$-HSD2) deficiency is a rare autosomal recessive form of congenital adrenal hyperplasia $(\mathrm{CAH})$. We report the genetic basis of $3 \beta$-HSD2 deficiency arising from uniparental isodisomy (UPD) of chromosome 1. We describe a term undervirilized male whose newborn screen indicated borderline CAH. The patient presented on the $7^{\text {th }}$ day of life in salt-wasting adrenal crisis. Steroid hormone testing revealed a complex pattern suggestive of $3 \beta$-HSD deficiency. Chromosomal microarray and single nucleotide polymorphism analysis revealed complete UPD of chromosome 1 . Sanger sequencing of HSD3B2 revealed a previously described missense mutation, c.424G>A (p.E142K) in homozygous state, thus confirming the diagnosis of $3 \beta$-HSD2 deficiency. We provide evidence of the existence of an uncommon mechanism for HSD3B2 gene-related CAH arising from UPD of chromosome 1 .
\end{abstract}

Keywords: Steroid 3 $\beta$-HSD2 deficiency, HSD3B2 gene, uniparental isodisomy

\section{Introduction}

Deficiency of 3-beta hydroxysteroid dehydrogenase type II (3 $\beta$-HSD2) is a rare autosomal recessive form of congenital adrenal hyperplasia $(\mathrm{CAH})$. In humans, $3 \beta$-HSD2 is predominantly expressed in the adrenal glands and gonads (1) and its encoding gene, HSD3B2 (MIM*613890), is located on chromosome $1(2,3)$. The enzyme $3 \beta$-HSD2 oxidizes and isomerizes $\Delta^{5}$-steroids, namely, pregnenolone, 17-hydroxypregnenolone (17-OH Preg) and dehydroepiandrosterone into corresponding $\Delta^{4}$-ketosteroids (4). Deficiency of the enzyme impacts the steroid hormone pathway by disrupting the biosynthesis of mineralocorticoid, corticosteroid, and sex hormones. Typically, 3 $\beta$-HSD2 enzyme deficiency results in cortisol deficiency, salt wasting, and male undervirilization. However, depending on the degree of enzyme deficiency and activity of the 3-beta hydroxysteroid dehydrogenase type I (3 $\beta$-HSD1) enzyme, a similar enzyme produced in the skin and placenta, milder presentation may occur (5). This variability in clinical presentation should 
prompt clinicians to seek clarification of the diagnosis using molecular methods.

Increased utilization of single nucleotide polymorphism (SNP) array in clinical practice has led to the recognition of uniparental isodisomy (UPD) that either disrupts imprinting patterns or unmasks autosomal recessive alleles (6). Reports on UPD as an underlying molecular mechanism of CAH are scarce (7). There are reported cases of UPD involving the two most common forms of CAH, steroid 21-hydroxylase (8) and 11 - $\beta$-hydroxylase deficiency (9). Here, we report the first patient affected by HSD3B2-related CAH uncovered by UPD of chromosome 1. In general, UPD of chromosome 1 has been infrequently reported in other disease conditions (10).

\section{Case Report}

Our patient is a 7-day-old male infant born at 37 weeks 5 days gestation. He was taken to his primary care physician with complaints of poor weight gain and vomiting and was referred to our hospital.

The infant was the product of an uncomplicated pregnancy, born to Caucasian parents. His birth length was $50.8 \mathrm{~cm}$ $\left(50^{\text {th }}\right.$ percentile), birth weight 3400 grams $\left(50^{\text {th }}\right.$ percentile), and head circumference $38 \mathrm{~cm}$ ( $75^{\text {th }}$ percentile). Physical examination was significant for hypotonia, non-specific dysmorphic facial findings including slight frontal bossing, hypotelorism, low nasal bridge and anteverted nares. Also noted was perineal hypospadias, bifid scrotum, penile chordee, and descended testes bilaterally. As part of the work-up for his nonspecific dysmorphic facies and hypotonia, an oligonucleotide microarray and a SNP analysis was sent. Also, at newborn screening, the patient was found to have a 17-hydroxyprogesterone (17-OHP) level of $33.2 \mathrm{ng} / \mathrm{mL}$, borderline for his birthweight (normal limits $<30$, borderline is $30-74$, and presumptive positive is $\geq 75$ ). Laboratory evaluation revealed hyponatremia with a serum sodium level of $131 \mathrm{mEq} / \mathrm{L}$ (reference 135-145 mEq/L) with concurrent hyperkalemia and a potassium level of 7.9 $\mathrm{mEq} / \mathrm{L}$ (reference 3.5-4.5 $\mathrm{mEq} / \mathrm{L}$ ). He was admitted to the pediatric intensive care unit and started on hydrocortisone, fludrocortisone, and sodium chloride supplementation. Steroid hormone testing obtained before treatment revealed a complex pattern suggestive of $3 \beta$-HSD deficiency. Steroid hormone determinations revealed the following abnormal values: $17-\mathrm{OH}$ Preg $119.0 \mathrm{nmol} / \mathrm{L}$ (reference 0.3-26.2 nmol/L), 17-OHP $16.9 \mathrm{nmol} / \mathrm{L}$ (reference 1.3-6.4 nmol/L), dehydroepiandrosterone $95.4 \mathrm{nmol} / \mathrm{L}$ (reference 1.7-26.4 $\mathrm{nmol} / \mathrm{L}$ ), progesterone $1.8 \mathrm{nmol} / \mathrm{L}$ (reference <0.3-0.5 $\mathrm{nmol} / \mathrm{L}$ ), cortisol $1462.3 \mathrm{nmol} / \mathrm{L}$ (reference 77.3-303.5 $\mathrm{nmol} / \mathrm{L}$ ), 11 -deoxycortisol $9.9 \mathrm{nmol} / \mathrm{L}$ (reference $\leq 5.9$ $\mathrm{nmol} / \mathrm{L}$ ), 11 -desoxycorticosterone $0.2 \mathrm{nmol} / \mathrm{L}$ (reference
1.0-2.7 nmol/L), and androstenedione $9.7 \mathrm{nmol} / \mathrm{L}$ (reference $<1.8 \mathrm{nmol} / \mathrm{L}$ ). Other laboratory results included: adrenocorticotropic hormone $8.4 \mathrm{pmol} / \mathrm{L}$ (reference 1.3$10.6 \mathrm{pmol} / \mathrm{L}$ ) and testosterone $1.6 \mathrm{nmol} / \mathrm{L}$ (reference 0.7 $1.7 \mathrm{nmol} / \mathrm{L}$ ). Additional studies included chromosomal analysis, chromosomal microarray, and fluorescent in situ hybridization analysis (FISH) of sex-determining region $\mathrm{Y}$ (SRY).

The patient recovered from his acute illness, was discharged home on steroids and electrolyte replacements. He underwent urologic surgery to correct his urogenital anomalies.

\section{Genetic Analysis}

Chromosomal karyotype analysis was performed per standard technique. FISH studies were completed with Vysis SRY probe using standard technique. Chromosomal oligonucleotide microarray and SNP analysis was done using an Affymetrix CytoScanHD hg19 (NCBI build 37) whole genome array consisting of 1.9 million non-polymorphic markers and 750,000 SNP probes, with an average probe spacing of about $1.2 \mathrm{~kb}$. Data were extracted and processed using Affymetrix ChAS software (Affymetrix, version 1.2.2) and Nexus Copy Number (BioDiscovery, version 7) software. Chromosomal analysis revealed normal male complement, 46,XY. SRY was present by FISH study. Chromosomal oligonucleotide microarray and SNP analysis revealed complete UPD of chromosome 1 (Figure 1), a $264 \mathrm{~kb}$ deletion of $11 \mathrm{q} 14.1$, and a $517 \mathrm{~kb}$ duplication of $17 \mathrm{p} 13.2$. The microdeletion of $11 \mathrm{q} 14.1$ and microduplication of $17 \mathrm{p} 13.2$ did not involve genes associated with known human disorders. Since UPD can clinically unmask mutations implicated in autosomal recessive disorders, gene content of chromosome 1 was reviewed for candidates associated with autosomal recessive syndromic ambiguous genitalia.

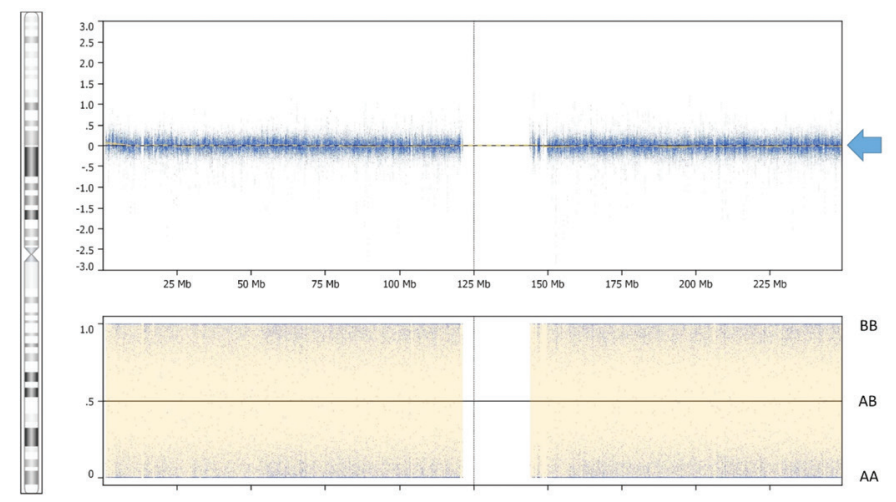

Figure 1. Uniparental isodisomy of chromosome 1. The figure demonstrates a normal copy number of chromosome 1 represented by probes in the top panel (blue arrow) averaging $\log _{2} R=0$ in the absence of $A B$ alleles shown in the bottom panel 
Several genes met this criterion, including HSD3B2. Sanger sequencing of $H S D 3 B 2$ revealed a previously described missense mutation, c.424G > A (p.E142K) in a homozygous state, thus confirming the diagnosis of $3 \beta$-HSD2. Parental samples were not available for our review to establish the origin of mutation and the parental origin of UPD.

\section{Discussion}

This is the first report to demonstrate the role of UPD on chromosome 1 as the molecular basis for the rare HSD3B2related $\mathrm{CAH}$, unmasking a known homozygous missense mutation, c.424G > A (p.E142K). Mutation c.424G > A (p.E142K) was uncovered as an incidental finding during a work-up for non-endocrine indication of dysmorphic appearance and hypotonia. This mutation has previously been implicated in the development of classic and nonclassic cases of HSD3B2-related CAH. Simard et al (11) reported an undervirilized male with salt-wasting $\mathrm{CAH}$ caused by compound heterozygosity of missense mutation p.E142K and a nonsense mutation p.W171X in HSD3B2. Pang et al (12) reported a female patient with non-classic presentation of $3 \beta$-HSD deficiency causing premature sexual hair growth and mild growth acceleration in childhood. Molecular analysis revealed compound heterozygous c. 1022C > T (p.Pro341Leu) and c.424G >A (p.E142K) mutations in HSD3B2.

Steroid hormone testing in our patient revealed a complex pattern of abnormalities. In addition to an elevated $17-\mathrm{OH}$ Preg (a 4.5-fold increase above the upper normal range) and dehydroepiandrosterone (a 3.6-fold increase above the upper normal range), the patient's profile revealed elevations of $\Delta^{4}$-ketosteroids and their products (progesterone, 17OHP, androstenedione, and cortisol). ACTH and testosterone were in the normal range. Elevations of $\Delta^{4}$-ketosteroids and their downstream metabolites in patients with $3 \beta$-HSD2 deficiency have been reported in the literature (1). Increased levels of 17-OHP, androstenedione, and testosterone are thought to occur due to preserved activity of $3 \beta$-HSD 1 encoded by a paralogue gene HSD3B1 expressed postnatally in skin and placenta (13). Therefore, it has been suggested that an elevated ratio of $\Delta^{5} / \Delta^{4}$-steroids could be a more informative biomarker to ascertain $3 \beta$-HSD2 deficiency (1). Genetic counseling for HSD3B2-related CAH involves a discussion of autosomal recessive inheritance and a $25 \%$ chance for parents to have another child with $\mathrm{CAH}$. However, the recurrence risk for CAH arising from UPD of a complete chromosome is considered much smaller owing to the mechanism underlying isodisomy formation. UPD in humans, as first described by Engel (14) in 1980, is the presence of a chromosome pair or portions of a chromosome pair (15) that originate from a single parent, thus designated maternal or paternal. Mechanistic explanations of UPD involve gamete complementation, trisomic rescue, monosomic rescue, or post-fertilization mitotic error $(16,17)$. The first two explanations would result in uniparental heterodisomy, while monosomic rescue and mitotic error and rescue may result in UPD. In all these cases, the original abnormality is thought to be a sporadic event without a significantly increased risk of recurrence, and parental chromosomal analysis would reveal normal results. Rarer mechanisms to generate complete UPD include correction of interchange trisomy or monosomy (in connection with a Robertsonian or reciprocal translocation), isochromosome formation, and correction of imbalance due to extra structurally abnormal chromosomes. In these rarer mechanisms, the parental karyotype should reveal a predisposing balanced or unbalanced chromosomal complement, and as such, may have an increased risk for recurrence. As parental samples were not unavailable, we could not establish the parental origin of UPD in this patient. However, the complete loss of heterozygosity of chromosome 1 in this patient suggests that monosomic rescue or mitotic error were the two most likely mechanisms of the observed UPD. In practice, since both of these mechanisms require the sequential occurrence of two abnormal events, UPD is usually a sporadic event with low risk of recurrence (18).

Follow-up and management of patients with HSD3B2related $\mathrm{CAH}$ have been well established (19). However, in formulating the management of autosomal recessive disorders unmasked by UPD, one needs to consider the possibility of other clinically relevant autosomal recessive alleles that could be revealed through the UPD-mediated loss of heterozygosity (20). Additional copy number variants identified by microarray may cause additive effects or modify the clinical presentation for this patient over time. We speculate this mechanism may have contributed to the non-specific dysmorphic features and hypotonia in this patient. Finally, to date, most phenotypes associated with UPD of chromosome 1 have been linked to the autosomal recessive disorders without evidence for the existence of a possible imprinting disorder.

In conclusion, with this case report, we provide evidence for the existence of an uncommon mechanism of HSD3B2related $\mathrm{CAH}$ arising from UPD of chromosome 1 that required the use of SNP-based array in the molecular evaluation of the patient, both from a diagnostic standpoint and recurrence risk assessment.

\section{Ethics}

Informed Consent: Consent to publish de-identified medical information has been provided by the patient's legal guardian.

Peer-review: Externally peer-reviewed. 


\section{Authorship Contributions}

Concept: Karin Panzer, Osayame A. Ekhaguere, Oleg A. Shchelochkov, Design: Oleg A. Shchelochkov, Data Collection or Processing: Karin Panzer, Osayame A. Ekhaguere, Jennifer Cook, Analysis or Interpretation: Benjamin Darbro, Oleg A. Shchelochkov, Literature Search: Karin Panzer, Osayame A. Ekhaguere, Oleg A. Shchelochkov, Writing: Karin Panzer, Osayame A. Ekhaguere, Oleg A. Shchelochkov.

Financial Disclosure: The authors declared that this study received no financial support.

\section{References}

1. Simard J, Ricketts ML, Gingras S, Soucy P, Feltus FA, Melner MH. Molecular biology of the 3beta-hydroxysteroid dehydrogenase/delta5delta4 isomerase gene family. Endocr Rev 2005;26:525-582. Epub 2005 Jan 4

2. Brett EM, Auchus RJ. Genetic forms of adrenal insufficiency. Endocr Pract 2015;21:395-399. Epub 2015 Feb 9

3. Goldman AS, Bongiovanni AM, Yakovac WC, Prader A. Study of delta-5, 3-beta-hydroxysteroid dehydrogenase in normal, hyperplastic and neoplastic adrenal cortical tissue. J Clin Endocrinol Metab 1964;24:894909.

4. OMIMEntry - *613890 -3-BETA-HYDROXYSTEROID DEHYDROGENASE 2; HSD3B2 Available at: http://omim.org/entry/613890\#0007. Accessed 2/22/2015, 2015.

5. Lutfallah C, Wang W, Mason JI, Chang YT, Haider A, Rich B, CastroMagana M, Copeland KC, David R, Pang S. Newly proposed hormonal criteria via genotypic proof for type II 3beta-hydroxysteroid dehydrogenase deficiency. J Clin Endocrinol Metab 2002;87:26112622 .

6. Conlin LK, Thiel BD, Bonnemann CG, Medne L, Ernst LM, Zackai EH, Deardorff MA, Krantz ID, Hakonarson H, Spinner NB. Mechanisms of mosaicism, chimerism and uniparental disomy identified by single nucleotide polymorphism array analysis. Hum Mol Genet 2010;19:1263-1275. Epub 2010 Jan 6

7. Liehr T. Cytogenetic contribution to uniparental disomy (UPD). Mo Cytogenet 2010;3:8.

8. Lopez-Gutierrez AU, Riba L, Ordonez-Sanchez ML, Ramirez-Jimenez S, Cerrillo-Hinojosa M, Tusié-Luna MT. Uniparental disomy for chromosome 6 results in steroid 21-hydroxylase deficiency: evidence of different genetic mechanisms involved in the production of the disease. J Med Genet 1998;35:1014-1019.
9. Matsubara K, Kataoka N, Ogita S, Sano S, Ogata T, Fukami M, Katsumata N. Uniparental disomy of chromosome 8 leading to homozygosity of a CYP11B1 mutation in a patient with congenital adrenal hyperplasia: implication for a rare etiology of an autosomal recessive disorder. Endocr J 2014;61:629-633. Epub 2014 Mar 13

10. Nimmo G, Monsonego S, Descartes M, Franklin J, Steinberg S, Braverman N. Rhizomelic chrondrodysplasia punctata type 2 resulting from paternal isodisomy of chromosome 1. Am J Med Genet A 2010;152:1812-1817.

11. Simard J, Rhéaume E, Sanchez R, Laflamme N, de Launoit Y, Luu-The V, van Seters AP, Gordon RD, Bettendorf M, Heinrich U, et al. Molecular basis of congenital adrenal hyperplasia due to 3 beta-hydroxysteroid dehydrogenase deficiency. Mol Endocrinol 1993;7:716-728.

12. Pang S, Wang W, Rich B, David R, Chang YT, Carbunaru G, Myers SE, Howie AF, Smillie KJ, Mason JI. A novel nonstop mutation in the stop codon and a novel missense mutation in the type II 3betahydroxysteroid dehydrogenase (3beta-HSD) gene causing, respectively, nonclassic and classic 3beta-HSD deficiency congenital adrenal hyperplasia. J Clin Endocrinol Metab 2002;87:2556-2563.

13. Simard J, Couet J, Durocher F, Labrie Y, Sanchez R, Breton N, Turgeon C, Labrie F. Structure and tissue-specific expression of a novel member of the rat 3 beta-hydroxysteroid dehydrogenase/delta 5-delta 4 isomerase (3 beta-HSD) family. The exclusive 3 beta-HSD gene expression in the skin. J Biol Chem 1993;268:19659-19668.

14. Engel E. A new genetic concept: uniparental disomy and its potential effect, isodisomy. Am J Med Genet 1980;6:137-143.

15. Kotzot D. Complex and segmental uniparental disomy updated. J Med Genet 2008;45:545-556. Epub 2008 Jun 4

16. Spence JE, Perciaccante RG, Greig GM, Willard HF, Ledbetter DH, Hejtmancik JF, Pollack MS, O'Brien WE, Beaudet AL. Uniparental disomy as a mechanism for human genetic disease. Am J Hum Genet 1988;42:217-226

17. Gardner RJ M, Sutherland GR, Shaffer LG. Chromosome abnormalities and genetic counseling. New York, Oxford University Press, 2004.

18. Gardner and Sutherland Chromosome Abnormality and Genetic Counseling. $3^{\text {rd }}$ ed. 198 Madison Avenue, New York, New York, 10016 : Oxford University Press, 2003:314-315.

19. Miller WL, Auchus RJ. The molecular biology, biochemistry, and physiology of human steroidogenesis and its disorders. Endocr Rev 2011;32:81-151. Epub 2010 Nov 4

20. Manoli I, Golas G, Westbroek W, Vilboux T, Markello TC, Introne W, Maynard D, Pederson B, Tsilou E, Jordan MB, Hart PS, White JG, Gahl WA, Huizing M. Chediak-Higashi syndrome with early developmental delay resulting from paternal heterodisomy of chromosome 1 . Am J Med Genet A 2010;152:1474-1483. 